investigated risk factors of depression in SLE patients, and the results are inconsistent. This study evaluated the prevalence of, and risk factors for, depression in ethnically homogeneous Korean SLE patients.

Methods: In this study, 505 consecutive SLE patients were enrolled from the Korean Lupus Network registry. Demographic variables, clinical manifestations, laboratory findings, physician global assessment, and SLEDAI-2000 and SLICC damage index were recorded at enrollment. Patients were identified as having depressive symptoms using the Korean version of the Beck Depression Inventory (BDI) with a cut-off $\geq 16$, and categorised into four groups. Multivariable logistic regression analyses were performed to identify independent risk factors for depression defined as a BDI score $>16$.

Results: Of the 505 patients, $97(19.2 \%)$ were diagnosed with depression Patients with a higher BDI score were older, more likely to be a current smoker, and had a SLICC score $>1$. Conversely, they had lower income and educational levels. Regarding the serologic findings, patients with a higher BDI score had lower anti-double-stranded DNA positivity and higher anticardiolipin (aCL) positivity. On multivariate analysis, the following factors were associated with depression: current smoking status (OR 2.533, $\mathrm{p}=0.049$ ), aCL-positivity (OR 2.009, $\mathrm{p}=0.035$ ), and a SLICC damage index score $>1$ (OR 2.781, $\mathrm{p}=0.039$ ). On the other hand, high-level education (OR $0.253, \mathrm{p}=0.024)$ and a high income (OR 0.228 , $\mathrm{p}=0.008$ ) were negatively associated with depression

Conclusions: Our results show that depression is prevalent in patients with SLE and multiple factors are associated with depression in SLE. These data could help guide target programs for those at high risk of depression in SLE.

Disclosure of Interest: None declared

DOI: 10.1136/annrheumdis-2018-eular.2741

\section{THU0364 RELATIONSHIP BETWEEN DISEASE ACTIVITY INDEX SCORES AND PHYSICIAN GLOBAL ASSESSMENT IN EARLY AND NON-EARLY SYSTEMIC LUPUS ERYTHEMATOSUS}

${ }^{1}$ M. Garabaiiu, V. Sadovici-Bobeica ${ }^{1}$, L. Mazur-Nicorici' ${ }^{1}$ M. Cebanu², V. Salaru ${ }^{3}$ M. Mazur ${ }^{1} .{ }^{1}$ Rheumatology, ${ }^{2}$ Medical Emergencies; ${ }^{3}$ Family Medicine, State University of Medicine and Pharmacy "Nicolae Testemitanu", Chisinau, Moldova, Republic of Ireland

Objectives: To evaluate the disease activity and to compare it to physician's global assessment in patients with early (early SLE) and non-early systemic lupus erythematosus

Methods: Performed case-control study included SLE patients that fulfilled SLICC classification criteria, 2012. The research included two groups: patients with early SLE - first group (disease duration less than 24 months) and non-early SLE - second group (disease duration more than 24 months). The disease activity was assessed by SLEDAI-2K and SLAM. Physician global assessment (PhGA) was rated by $0-100$ numeric score. We correlated disease activity indices with physician global assessment by Pearson coefficient

Results: A total of 96 SLE patients were analysed. First group included 45 patients with female:male ratio 14:1. The second group included 51 patients, female:male ratio 1:49. The disease activity indices: SLEDAI and SLAM denoted high disease activity level in both groups. PhGA didn't correlate with SLEDAI $(r=0,28, p>0,05)$ in the first group, while a statistically significant correlation was determined with SLAM index $(r=0,39, p=0.007)$. In the second group we found a moderate statistical significant correlation of PhGA with SLAM $(r=0,53, p=0.0001)$ and weak, but also statistical significant relationship with SLEDAI $(r=0,35$, $p=0.01$ ). There is a better correlation of PhGA assessment and SLAM in both study groups, which can be explained by the presence of subjective components in appreciation of this index. Patient's better appreciation of their condition in the group with longer disease duration (statistical significant correlation of PhGA and both indices:SLAM and SLEDAI), probably, is beacause this patients know better to appreciate their disease, and patients with early SLE tend to underestimate their general condition

\begin{tabular}{lcc}
\hline Parameters of the disease & Gr I, Nr 45 & Gr II, Nr 51 \\
\hline Age at study entry $\pm S D$ (range), years & $41.18 \pm 14.0(20-75)$ & $43.51 \pm 12.3(22-67)$ \\
Disease duration $\pm S D$ (range), month & $10.14 \pm 9.10(0.1-24)$ & $159.71 \pm 94.53(31-432)$ \\
SLAM $\pm S D$ (range), points & $9.31 \pm 4.87^{3-24}$ & $8.08 \pm 4.38^{1-22}$ \\
SLEDAI $\pm S D$ (range), points & $11.13 \pm 7.58^{2-34}$ & $7.33 \pm 5.54(0-23)$ \\
PhGA $\pm S D$ (range), points & $44.02 \pm 18.75^{10-80}$ & $47.73 \pm 22.63^{5-92}$ \\
\hline
\end{tabular}

Conclusions: In patients with early SLE PhGA correlated with SLAM, while in patients with non-early lupus PhGA correlated with both insices - SLAM and SLEDAI-2K. A better correlation of PhGA with SLAM can be esplained by the presence of multiple components in this tool and also subjective data as fatigue or cognitive disfunction.

Disclosure of Interest: None declared

DOI: 10.1136/annrheumdis-2018-eular.3862

\section{THU0365 \\ POTENTIAL PREDICTIVE FACTORS INFLUENCING ESSDAI OF PRIMARY SJÖGREN'S SYNDROME} PATIENTS

${ }^{1}$ M. Maślińska, J. Dmowska-Chalaba', M. Mańczak², B. Kwiatkowska ${ }^{3} .{ }^{1}$ Early Arthritis Clinic; ${ }^{2}$ Department of Gerontology, Public Health and Didactics; ${ }^{3}$ Early Arthritis Clinic, National Institute of Geriatrics, Rheumatology and Rehabilitation, Warsaw, Poland

Background: The useful tool to assessing disease activity in primary Sjögren's syndrome(pSS) is an EULAR Sjögren's syndrome disease activity index (ESS DAI)[.

Objectives: The aim of this study was indication of laboratory and clinical factors affecting the ESSDAI in pSS patients.

Methods: 75 pSS patients were included; 65 (87\%) female, 10 (13\%)men; mean age 50 years $S D \pm 15$. The tests included:basic laboratory tests, rheumatoid factor $(\mathrm{RF})$, erythrocyte sedimentation rate, $\mathrm{CRP}$, gammaglobulins serum concentration, C4 and C3 component of complement, antinuclear antibodies (ANA) - IF test HEp-2000, anti-SS-A and anti-SS-B antibodies evaluation with semi-quantitative immunoblotting, standard ELISA assays for serum cytokines levels (BAFF APRIL, FLT-3L, TNF- $\beta$, IL-21) and $\beta 2$-microglobulin. Biopsy of minor salivary gland with the histopathological evaluation (focus score-FS) and the immuno chemistry was also performed with the CD3+, CD4 +, CD19 +, CD21 + CD35 +cells presence assessment. The Schirmer's test and ocular staining score (OSS) were performed. The Bioethics Committee aproval was obtained. Statistics: U Mann-Whitney (continuous variables) tests, Spearman correlation coefficient (correlations between quantative variables) with statistical significance set at $\mathrm{p}<0.05$.

Results: ESSDAI depends on FS, the presence of CD4 +, CD3 +cells in the minor salivary glands infiltrates, RF and cryoglobulins $(p<0.05)$. The division of pSS subjects into two subgroups (ESSDAI $>5 ;<5$ ) revealed, that the autoantibodies as anti-SS-A and anti-SS-B, influence the severity of the disease $(p=0,046$ $p=0015$ respectively). ESSDAI positively correlated with OSS, but not with the Schirmer's test, other tested cytokines, ESR, CRP and gammaglobulins concentration - yet interestingly ESSDAI correlates negatively with lgG4 (rho=-0,435).

Conclusions: The results confirm, that organ-related complications are influenced by inflammatory activity. This activity is expressed by mononuclear cell infiltrates (FS), which consist primarily of T-lymphocytes (indicators of active and early stage inflammation). However, contrary to other observations, ${ }^{3}$ no correlation between ESSDAI and cytokines or $\beta 2$ - microglobulin was found. The correlation of ESSDAI with the presence of pSS marker autoantibodies (anti-SS-A, ant SS-B antibodies), as well as with non-specific ones (RF or cryoglobulins), indicates the immunological disease activity and overactivity of $B$ lymphocytes as suspected. The reduction of IgG4 concentration in pSS patients correlating with higher ESSDAI can be associated with breaking the autotolerance and lack of stimulation of IgG4 production. But the role and importance of lgG4 in immunological processes both as an activator of dependent autoimmune diseases and, on the other hand, the marker of induction of immune tolerance requires further research.

\section{REFERENCES:}

[1] Seror R, Bowman SJ, Brito-Zeron P, et al. EULAR Sjögren's syndrome disease activity index (ESSDAI): a user guide. RMD Open 2015;1: e000022.

[2] Risselada AP, Kruize AA, Bijlsma JW. Clinical applicability of the EULAR Sjogren's syndrome disease activity index: a cumulative ESSDAI score adds in describing disease severity. Ann Rheum Dis 2012;71(4):631.

[3] Seror R, Theander E, Bootsma H, et al. Outcome measures for primary Sjögren's syndrome: a comprehensive review. J Autoimmun 2014;51:51-6.

Disclosure of Interest: None declared

DOI: 10.1136/annrheumdis-2018-eular.4241

\section{THU0366 \\ STUDY OF THE ROLE OF MICRO-RNA 20A EXPRESSION IN SYSTEMIC LUPUS ERYTHEMATOSUS IN AN EGYPTIAN COHORT}

${ }^{1}$ M.S. Elkhalifa, M. Zehairy ${ }^{1}$, M. Tayel ${ }^{1}$, A. Elkeraie ${ }^{2}$, D. Elkaffash ${ }^{3}$, N. Baddour ${ }^{4}$. ${ }^{1}$ Rhe umatology unit, Interal Medicine department, ${ }^{2}$ Nephrology unit, Internal medicine department, ${ }^{3}$ Clinical and Chemical Pathology, ${ }^{4}$ pathology, Faculty of Medicine, Alexanderia University, Egypt, Alexanderia, Egypt

Background: Micro-RNAs are small noncoding RNAs that act as cytoplasmic post-transcriptional gene expression regulators by targeting their complementary messenger RNA. They regulate several inflammatory, immunologic and oncogenic pathways. ${ }^{(1)}$ MicroRNAs are differentially expressed in patients with sys temic lupus erythematosus (SLE), especially in association with lupus nephritis. $(2,3)$ The positive miRNA list in SLE patients in different studies presents relatively 
limited overlap. The heterogeneity of patient ethnicity and variety in detection method may in part explain some of the discrepancies. ${ }^{(4)}$

Objectives: to study the role of micro-RNA 20a expression in SLE in an Egyptian cohort and its role as a potential biomarker of lupus nephritis.

Methods: Expression levels of micro-RNA-20a extracted from peripheral blood mono-nuclear cells determined using quantitative reverse transcription-polymerase chain reaction assay. A total of 90 plasma samples were obtained from 30 SLE patients without clinical and laboratory evidence of lupus nephritis, 30 SLE patients with lupus nephritis and 30 healthy control subjects.

Results: The expression of micro-RNA-20a in SLE patients was significantly lower than the expression in normal healthy control, $\mathrm{p}<0.001$. In addition the Roc curve of micro-RNA-20a showed that micro-RNA-20a expression levels can significantly discriminate between lupus patients with and without lupus nephritis at a cut off level $\leq 9.3 \times 10-6$ with a specificity of $76.67 \%$ and sensitivity of $96.67 \%$. We also found a significant correlation between micro-RNA-20a expression levels and the pathological activity index of renal biopsy, while there was no significant correlation between micro-RNA-20a expression level and the pathological chronicity index.

Conclusions: The expression level of micro-RNA-20a could be considered a diagnostic marker of SLE. Also, the expression level of micro-RNA-20a could be considered a potential biomarker for recognition of renal involvement in SLE patients.

\section{REFERENCES:}

[1] Schetter AJ, Heegaard $\mathrm{NH}$, Harris CC. Inflammation and cancer: interweaving microRNA, free radical, cytokine and p53 pathways. Carcinogenesis 2010;31:37-49.

[2] Dai Y, Huang YS, Tang M, Lv TY, Hu CX, Tan YH, et al. Microarray analysis of microRNA expression in peripheral blood cells of systemic lupus erythematosus patients. Lupus 2007;16:939-46.

[3] Te JL, Dozmorov IM, Guthridge JM, Nguyen KL, Cavett JW, Kelly JA, et al. Identification of unique microRNA signature associated with lupus nephritis. PLoS One 2010;5(5): e10344.

[4] Wang Z, Chang C, Peng M, Lu Q. Translating epigenetics into clinic: focus on lupus. Clin Epigenetics 2017; 9:78.

Disclosure of Interest: None declared

DOI: 10.1136/annrheumdis-2018-eular.2800

\section{THU0367 PREVALENCE AND SIGNIFICANCE OF ANTI- PHOSPHATIDYLSERINE ANTIBODIES: A POOLED ANALYSIS IN 5992 PATIENTS}

${ }^{1}$ M. Radin, I. Cecchi ${ }^{1}$, E. Rubini ${ }^{1}$, S. Karen ${ }^{2}$, D. Roccatello ${ }^{1}$, M. Mahler ${ }^{3}$, S. Sciascia'. ${ }^{1}$ Clinical and Biological Sciences, UNIVERSITÀ DEGLI STUDI DI TORINO, Turin, Italy; ${ }^{2}$ Copenhagen University Hospital, Copenhagen, Denmark;

${ }^{3}$ Inova Diagnostics, San Diego, USA

Background: The current classification criteria for antiphospholipid syndrome (APS) include three laboratory tests: lupus anticoagulant, anti-cardiolipin, and anti-b2 glycoprotein-II.

Among the so-called 'extra-criteria' aPL tests, anti-phosphatidylserine (aPS) antibodieshave been proposed as an additional tool to be considered when patient is suspected for having APS. However the exact prevalence of aPS antibodies, and their independent role as risk factor for developing clinical manifestations of APS, is uncertain.

Objectives: To estimate the prevalence of aPS antibodies in patients with clinical manifestations of APS, by systematically reviewing the literature.

Methods: A detailed literature search was applied a priori to Ovid MEDLINE, InProcess and Other Non-Indexed Citation 1989 to present and to abstracts from EULAR and ACR/ARHP Annual Meetings (2011-2017) (figure 1).

Results: Data from 5992 patients from 20 studies were analysed (table 1). In APS patients, we report an overall estimated median prevalence of aPS antibodies of $55 \%$ [S.D \pm 21.1 , range $29 \%-87 \%$ ] and $35 \%$ [S.D. $\pm 17.9,16-65 \%$ ] for $\lg G$ and IgM, respectively. aPS antibodies were more frequently found in patients with known APS, when compared to patients with thrombosis/pregnancy loss or SLE (IgG mean $55 \% \pm 28.9,30 \pm 19.6,22 \pm 13$; IgM $35 \pm 4.3,1 \pm 2.8,14 \pm 8.3$, respectively, $\mathrm{p}<0.05)$. In detail, patients were distributed as follow:366 APS patients in 7 studies [55\% aPS IgG/37\% aPS IgM-positive; in more detail, 78 primary APS in 2 studies (64\% aPS IgG/48\% aPS IgM-positive), 29 secondary APS in 2 studies (37\%aPS IgG/24\% aPS IgM-positive) and 259 not specified], 787SLE patients in 7 studies (22\%aPS IgG/14\% aPS IgM-positive), 24aPLasymptomatic carriers in one study (21\% aPS IgG/25\% aPS IgM-positive), 3565 patients with cardiovascular accidents in 4 studies (18\% aPS IgG/7\% aPS IgM-positive), 1250 patients with pregnancy morbidity in 6 studies ( $30 \%$ aPS IgG/1\% aPS IgM-positive) and 952 healthy controls.

\begin{tabular}{|c|c|c|c|c|}
\hline DIAGNOSIS & $\begin{array}{c}\text { Number } \\
\text { of } \\
\text { patients } \\
\text { included } \\
\text { in the } \\
\text { analysis }\end{array}$ & $\begin{array}{c}\% \text { of } \\
\text { positive } \\
\text { patients for } \\
\text { anti aPS } \\
\text { IgG } \\
\text { antibodies }\end{array}$ & $\begin{array}{c}\% \text { of } \\
\text { positive } \\
\text { patients for } \\
\text { anti aPS } \\
\text { lgM } \\
\text { antibodies }\end{array}$ & $\begin{array}{l}\text { Studies } \\
\text { included in } \\
\text { the analysis }\end{array}$ \\
\hline APS $^{*}$ & 366 & 55 & 37 & $\begin{array}{c}\text { Roggenbuck } \\
\text { et al. } 2016 \\
\text { Khoger et al. } \\
2014 \\
\text { Jaskowski et } \\
\text { al. } 2009 \\
\text { Lopes et al. } \\
2004 \\
\text { Musial et al. } \\
2003 \\
\text { Ware Branch } \\
\text { et al. } 1997\end{array}$ \\
\hline PAPS & 78 & 64 & 48 & $\begin{array}{c}\text { Roggenbuck } \\
\text { et al. } 2016 \\
\text { Musial et al. } \\
2003\end{array}$ \\
\hline Secondary APS & 29 & 37 & 24 & $\begin{array}{c}\text { Roggenbuck } \\
\text { et al. } 2016 \\
\text { Bertolaccini } \\
\text { et al. } 1998\end{array}$ \\
\hline SLE & 787 & 22 & 14 & $\begin{array}{c}\text { Nojima et al. } \\
2014 \\
\text { Fialova et al. } \\
2003 \\
\text { Musial et al. } \\
2003 \\
\text { Amoroso et } \\
\text { al. } 2003 \\
\text { Palomo et al. } \\
2002 \\
\text { Bertolaccini } \\
\text { et al. } 1998 \\
\text { Toschi et al. } \\
1993\end{array}$ \\
\hline aPL+, asymptomatic & 24 & 21 & 25 & $\begin{array}{c}\text { Roggenbuck } \\
\text { et al. } 2016\end{array}$ \\
\hline Cardiovascularaccidents ${ }^{\star *}$ & 3565 & 21 & 7 & $\begin{array}{c}\text { Carmel- } \\
\text { Neiderman } \\
\text { et al. } 2017 \\
\text { Bu et al. } \\
2016 \\
\text { Saidi et al. } \\
2009 \\
\text { Khales et al. } \\
2005\end{array}$ \\
\hline PregnancyMorbidity** & 1250 & 30 & 1 & $\begin{array}{c}\text { Ching et al. } \\
2013 \\
\text { Sater et al. } \\
2012 \\
\text { Jaskowski et } \\
\text { al. } 2009 \\
\text { Alijotas-Reig } \\
\text { et al. } 2010 \\
\text { Ulcova- } \\
\text { Gallova et al. } \\
2005 \\
\text { Ware Branch } \\
\text { et al. } 1997\end{array}$ \\
\hline
\end{tabular}

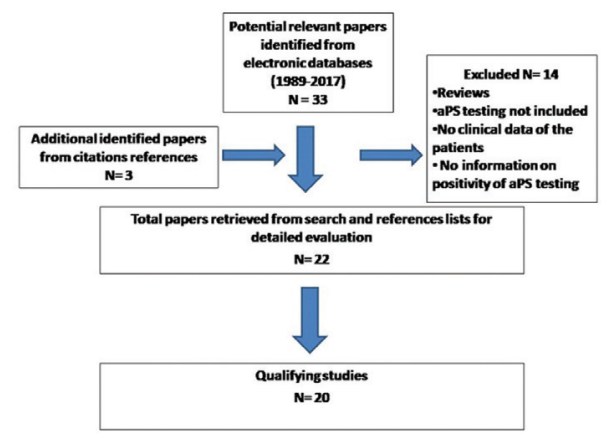

Conclusions: While aPS are frequently detected in patients with known APS, their added diagnostic value and clinical role in patients with thrombosis/pregnancy loss and/or concomitant autoimmune disease remain uncertain. 